This is an open access article under the CC BY-NC-ND license

Issue IV, 22 November 2021

e-ISSN 2707-9481

Institute of Metallurgy and Ore Beneficiation, Satbayev University, Almaty, Kazakhstan

ISBN 978-601-323-252-2

https://doi.org/10.31643/2021.06

Semushkina L.V.

Institute of Metallurgy and Ore Beneficiation,

Satbayev University,

Almaty, the Republic of Kazakhstan

E-mail: syomushkina.lara@mail.ru

ORCID ID 0000-0001-8925-5250
Narbekova S.M.

Institute of Metallurgy and Ore Beneficiation,

Satbayev University,

Almaty, the Republic of Kazakhstan

E-mail: s.narbekova@mail.ru

ORCID ID 0000-0002-7325-754X

\title{
On the possibility of flotation processing of technogenic gold-containing waste from enrichment plants
}

\begin{abstract}
The aim of the work is the flotation processing of gold-containing tailings using composite flotation (CF) agents. According to the results of chemical analysis, the studied tailings sample contains $0.39 \mathrm{~g} / \mathrm{t}$ gold. The main part of the initial tailings sample is represented by rock-forming minerals such as quartz, clinochlore, microcline, tremolite, albite, calcite, and muscovite. According to the results of the rational analysis, $39.50 \%$ of gold is in the hard-to-recover form with quartz; $28.87 \%$ is in the form of fine-grained gold; $31.63 \%$ is in intergrowths with sulfides and rocks. The optimum reagent scheme of flotation processing of tailings was chosen: degree of regrinding of $95 \%$ of grade $-0,074 \mathrm{~mm}$, consumption of sodium butyl xanthate of $100 \mathrm{~g} / \mathrm{t}$, consumption of foaming agent T-92 of $30 \mathrm{~g} / \mathrm{t}$. Under the chosen reagent scheme the gold-containing concentrate containing $6,4 \mathrm{~g} / \mathrm{t}$ gold at the recovery of $49,68 \%$ was obtained. Preliminary regrinding of tailings allows to increase the gold recovery in the blanks concentrates by $27.96 \%$. The reagent scheme of flotation of gold-containing tailings with the application of composite flotation (CF) agent was tested. A composition of sodium butyl xanthate and reaeflot was used as a composite flotation reagent for the improvement of gold extraction from flotation tailings. Application of composite flotation (CF) agent pre-treated on the dispersant increases gold recovery into gold-containing concentrate by $4.65 \%$, in comparison with the basic collector sodium butyl xanthogenate. Consumption of flotation agent CF is reduced by $20 \%$.
\end{abstract}

Keywords: anthropogenic waste, flotation, composite reagent, concentrate.

Cite this article as: Semushkina L.V.; Narbekova S.M. (2021). On the possibility of flotation processing of technogenic gold-containing waste from enrichment plants. Challenges of Science. Issue IV, 2021, pp. 40-47. https://doi.org/10.31643/2021.06

\section{Introduction}

Over the many years of mining enterprises' operation, billions of tons of ore mining and concentration wastes have accumulated in dumps and tailings. The maintenance of these facilities requires significant capital and material costs, and the stockpiled crushed enrichment waste pollutes the soil and the atmosphere through water and wind erosion. The issue of improving environmental safety can be solved both by creating technologies for the processing of stockpiled enrichment waste and by maximizing the recovery of all useful components.

In this regard, the use of modern approaches, new flotation reagents, and modernized equipment for enrichment of mineral and technogenic raw materials is a priority when creating innovative 
technologies (Chanturiya V.A. et al. (2016), Magomedov D.R. et al. (2018), Abdykirova G.Zh. et al. (2020) [13].

The problem of finding effective reagents for flotation of non-ferrous and noble metals from manmade wastes is relevant (Matveyeva T.N. et al. (2017), Kianinia Y. et al. (2019), Erdenova M.B. et al. (2018), Semushkina L.V. et al. (2018) [4-7].

Thus, in the flotation of sulfide minerals application of such reagent as dithiopyrilmethane was tested. In flotation of gold-bearing ores, dithiopyrilmethane feeding into the pulp showed that it increases the extraction of gold-bearing arsenopyrite by $6 \%$ in the presence of basic sodium butyl xanthogenatecompared to the use of sodium butyl xanthogenate alone (Ivanova T.A. et al. (2018) [8].

Due to the increased processing of low-grade technogenic waste, the development of new innovative solutions for the extraction of base and noble metals with low production costs is required (Algebraistova N.K. et al. (2018), Fatahi M.R. et al. (2017), Xiao J. et al. (2017), GusevV.Yu. et al. (2018) [912].

Wastes of the gold extraction plant operating by gravitation and flotation scheme were investigated. Gold is in its native form and the form of intergrowths with pyrite. The main mass of the tailings is represented as quartz, muscovite, chlorite, albite, calcite, and dolomite. The possibility to enrichthe gold-containing tailings without regrinding by gravitation and flotation methods was studied. It was determined that the use of reagents combinations provides higher gold extraction in comparison with the application of butyl xanthate alone. The developed combined gravity-flotation beneficiation scheme allows to obtain gravity and flotation concentrates with a content of about $60 \mathrm{~g} / \mathrm{t}$ gold at a total metal recovery of about 63.6\% (Algebraistova N.K. et al. (2018) [13].

An increase of technical indicators of flotation can be achieved by using a combination of different collectors. Thus, during flotation of copper-zinc ore of Gaisky deposit butyl potassium xanthogenate; sodium butyl dithiophosphate; a mixture of thionocarbamate and dithiophosphate; as well as mixtures of these collectors in different ratios were used as collector reagents. The highest selectivity was obtained when using the composition of thionocarbamate and dithiophosphate as a collector reagent (Nikolayyev A.A. et al. (2016) [14].

Scientists are conducting research on creation of different dialkyldithiophosphates. The properties of dialkyldithiophosphates and the reagents containing them are greatly influenced by the strong surfaceactive properties of dialkyldithiophosphates. The surface-active properties in the series of dialkyldithiophosphates with the C4-C12 hydrocarbon chain length have been studied. It was found that the maximum sulfide recovery corresponds to dialkyldithiophosphate C10 (Riaboy V.I. et al. (2015) [15].

Thus, based on analysis of scientific and technical literature it is concluded that combination of different collectors, dispersion, and optimization of the composition of such reagents (increase or decrease of length of a hydrocarbon radical and its branching, introduction of additional component) leads to improvement of foaming, gathering and other properties.

\section{Research methods}

Modern research and analytical equipment were used for the studies: Optima 2000 DV atomic emission spectrometer; D8 ADVANCE X-ray diffractometer; Thermo Nicolet Avatar 370 FTIR spectrometer; Venus 200 PANalyical B.V. X-ray fluorescence spectrometer; JEOL JXA-8230 electron raster microscope, JEOL JXA-8230 electron scanning microscope. The technological equipment was used: a jaw crusher DMD160/100; ball mill 40ML-000PS; flotation machine FML; photometric sedimentometer FSH-6K; dispersant T18 digital ULTRA-TURRAX; laser particle analyzer Winner2000E; mechanical eraser MM-1.

The objects of the research were technogenic gold-containing tailings of Kazakhstani deposit and composite flotation (CF) agent. A composition of sodium butyl xanthogenate and reaflot was used as a flotation agent for the flotation of gold-containing tailings.

\section{Results and discussion}

The material composition and reagent regime of flotation of gold-containing tailings with the use of basic reagents were studied. 
X-ray phase, X-ray fluorescence, and chemical analyses were performed. X-ray phase analysis was performedon diffractometer D8 Advance (BRUKER), Cu-K $\alpha$ radiation. Processing of the obtained data of diffractograms and calculation of interplanar distances were performed using EVA software. The results of the X-ray phase analysis are presented in Table 1.

The main part of the initial sample of flotation tailings, according to the X-ray phase analysis results, is represented by rock-forming minerals such as quartz (41.2\%), clinochlore (20.1\%), microcline (14.3\%), tremolite $(13.1 \%)$, albite $(5.2 \%)$, calcite $(3.5 \%)$, muscovite $(2.6 \%)$. According to the results of chemical analysis, the studied sample of tailings contains $0.49 \mathrm{~g} / \mathrm{t}$ gold, $3.8 \%$ iron.

Table 1. Results of X-ray phase analysis of initial gold-containing flotation tailings

\begin{tabular}{|c|c|c|}
\hline Compound Name & Formula & $\mathrm{S}-\mathrm{Q}$ \\
\hline Quartz, syn & $\mathrm{SiO}_{2}$ & 41.2 \\
\hline Clinochlore (IIb-4) & $\mathrm{Mg} 4.882 \mathrm{Fe} 0.22 \mathrm{Al} 1.881 \mathrm{Si} 2.96 \mathrm{O} 10(\mathrm{OH}) 8$ & 20.1 \\
\hline Microcline, intermediate & KAISi3O8 & 14.3 \\
\hline Tremolite & (Ca1.97Na0.016Fe0.014)Mg5Si8O22(OH)2 & 13.1 \\
\hline Albite, low & $\mathrm{Na}(\mathrm{AlSi} 3 \mathrm{O} 8)$ & 5.2 \\
\hline Calcite & $\mathrm{Ca}(\mathrm{CO} 3)$ & 3.5 \\
\hline Muscovite-1M, syn & KAI2Si3AlO10(OH)2 & 2.6 \\
\hline
\end{tabular}

X-ray fluorescence analysis of the original tails was performed on a Venus 200 PANalytical B.V. Xray fluorescence spectrometer with wave dispersion. (PANalytycal B.V., Holland). According to the results of X-ray fluorescent analysis, the main mass in the primary sample of flotation tailings of the Bestobe ore deposit is silicon $-24.573 \%$, oxygen $-43.701 \%$, aluminum $-6.734 \%$, iron $-3.256 \%$, calcium $-3.115 \%$.

According to the results of rational analysis, $39.50 \%$ of gold is in the hard-to-recover form with quartz; $28.87 \%$ is in the form of fine gold; $31.63 \%$ is in intergrowths with sulfides and rocks.

Granulometric analysis of initial tailings sample with the distribution of gold by size classes by sieve method was performed. The results are shown in Table 2 . The results of the granulometric analysis showed that $71.76 \%$ of gold is in the class of less than 40 microns.

Table 2. Results of particle size analysis of initial gold-containing flotation tailings

\begin{tabular}{ccccc}
\hline Size class, $\mathrm{mm}$ & $\begin{array}{c}\text { Yield } \\
\%\end{array}$ & Au content, $\mathrm{g} / \mathrm{t}$ & $\nu \times \beta \mathrm{Au}$ & Distribution \% \\
\hline+0.1 & 1.18 & 1.69 & 1.99 & 5.63 \\
\hline$-0.1+0.071$ & 20.08 & 0.30 & 6.02 & 17.02 \\
\hline$-0.071+0.040$ & 15.22 & 0.13 & 1.98 & 5.59 \\
\hline$-0.040+0$ & 63.52 & 0.40 & 25.41 & 71.76 \\
\hline Total: & 100.00 & 0.35 & 35.40 & 100.00 \\
\hline
\end{tabular}

Dispersive analysis of initial tailings was performed on a photometric sedimentometer FSH-6K, which is designed to measure the particle size distribution of powders and suspensions with a particle size less than $\mathbf{3 0 0}$ microns. The instrument operates based on the Stokes sedimentation law and the LambertBeer law of radiation attenuation in turbid media. The sedimentation process is performed in the evenly mixed diluted suspension of a solid phase (ore) in the dispersion liquid (water) and is fixed by a change of intensity of light, passing through suspension, in which particles are sedimented. The apparatus determines the Stokes diameter of the particles. The Stokes diameter is the diameter of such spherical particle, the sedimentation rate of which is equal to the sedimentation rate of the non-spherical particles being examined. The instrument makes measurements of the optical density of the suspension at the level of 
optical slits at the time moments, calculated in advance according to Stokes law, corresponding to sedimentation of particles of the given size. Results of dispersion analysis are shown in Fig. 1.

The results of the analysis of variance indicate that in the initial sample of tailings the largest of the initial sample of tailings the largest part is the size classes of $15-20$ microns and $70-80$ microns.

(H)

LabNauchPribor LLC

PhotosedimentometerFSKh-6

\begin{tabular}{lc}
\multicolumn{1}{c}{ Initial values: } \\
Particle size range & $1.00-300.0 \mu \mathrm{m}$ \\
Powder material density & $2.89 \mathrm{~g} / \mathrm{cm}^{3}$ \\
Particle shape factor & 1.00 \\
Liquid phase density & $1.00 \mathrm{~g} / \mathrm{cm}^{3}$ \\
Viscosity of the liquid phase & $1.00 \mathrm{mPa} * \mathrm{~s}$
\end{tabular}

Measured: $14,04,2021$ at $13: 24$

Result file: fsh dat

\section{DISTRIBUTION STATISTICS}

Mean values:

Median diameter

Root Mean Square diameter

Mean Harmonic diameter $\quad 21.8 \mu \mathrm{m}$ Deviations:

Standard:

$61.4 \mu \mathrm{m}$

Root Mean Square

$63.9 \%$

Asymmetry coefficient

Dispersion

Specific surface area (mass)

0.7

$9449.1 \mathrm{um}^{2}$

Modes of distribution:

$\begin{array}{llll}17.8 & 67.1 & 178.6 & \mu \mathrm{m}\end{array}$

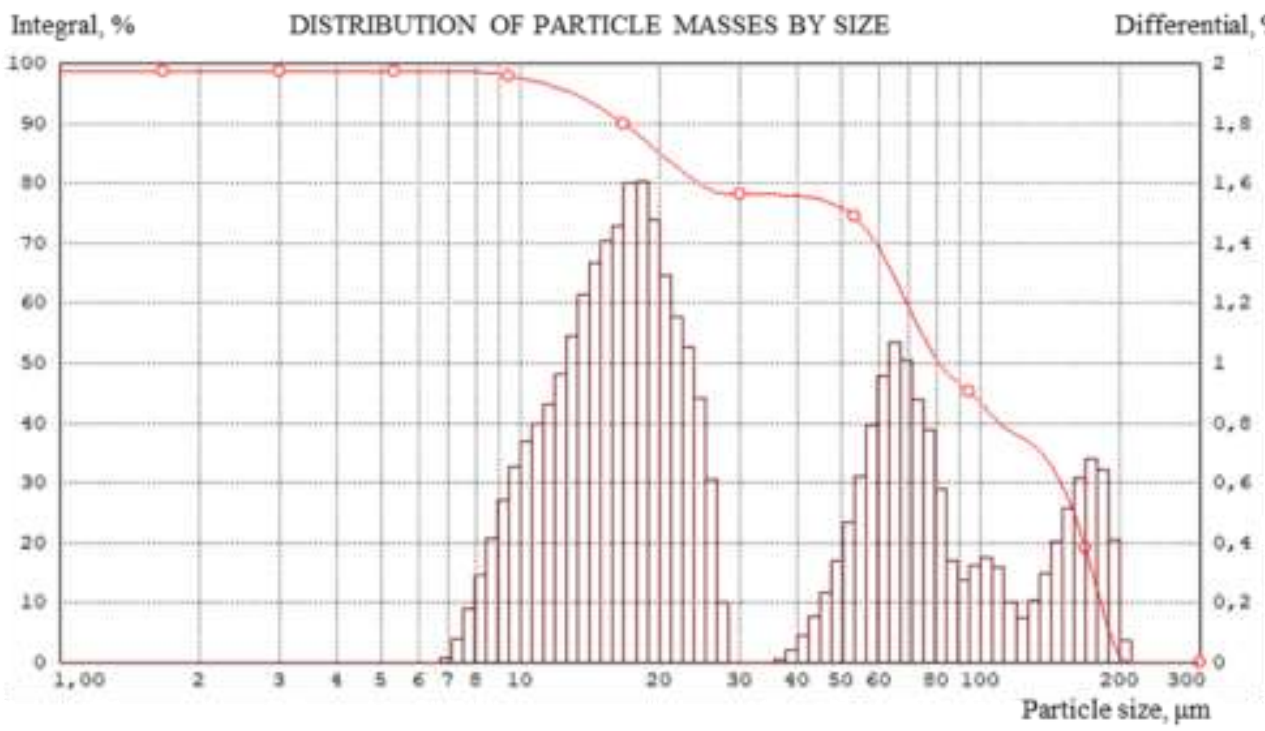

Last measurement

\begin{tabular}{|c|c|c|c|c|c|c|c|}
\hline $\begin{array}{l}\text { Larger, } \\
\mu \mathrm{m}\end{array}$ & $\%$ & $\begin{array}{c}\text { In the } \\
\text { interval, } \\
\mu \mathrm{m}\end{array}$ & $\%$ & $\begin{array}{c}\text { Larger, } \\
\mu \mathrm{m}\end{array}$ & $\%$ & $\begin{array}{c}\text { In the } \\
\text { interval, } \\
\mu \mathrm{m}\end{array}$ & $\%$ \\
\hline 1 & 98,7 & $0-1$ & 1,3 & 45 & 77,3 & $40-45$ & 0,6 \\
2 & 98,7 & $1-2$ & 0,0 & 50 & 75,9 & $45-50$ & 1,4 \\
3 & 98,7 & $2-3$ & 0,0 & 56 & 72,7 & $50-56$ & 3,2 \\
5 & 98,7 & $3-5$ & 0,0 & 63 & 66,7 & $56-63$ & 6,0 \\
7 & 98,7 & $5-7$ & 0,0 & 70 & 59,4 & $63-70$ & 7,3 \\
10 & 97,6 & $7-10$ & 1,1 & 80 & 51,0 & $70-80$ & 8,4 \\
12 & 96,0 & $10-12$ & 1,6 & 90 & 46,5 & $80-90$ & 4,4 \\
14 & 93,8 & $12-14$ & 2,2 & 100 & 43,5 & $90-100$ & 3,0 \\
20 & 84,9 & $14-20$ & 8,9 & 125 & 37,1 & $100-125$ & 6,4 \\
25 & 79,5 & $20-25$ & 5,5 & 140 & 33,5 & $125-140$ & 3,6 \\
28 & 78,1 & $25-28$ & 1,3 & 160 & 24,5 & $140-160$ & 9,0 \\
32 & 78,1 & $28-32$ & 0,1 & 180 & 11,4 & $160-180$ & 13,1 \\
36 & 78,1 & $32-36$ & 0,0 & 250 & 0,0 & $180-250$ & 11,4 \\
40 & 77,9 & $36-40$ & 0,1 & 300 & 0,0 & $250-300$ & 0,0 \\
\hline
\end{tabular}

Fig. 1. Dispersive analysis of initial gold-containing flotation tailings at FSH-6K 
The reagent mode of flotation of tailings enrichment with the use of basic reagents was tested. For the research, the initial tailings were reground in the laboratory ball mill 40ML-000PS up to $95 \%$ of the class $-0.074 \mathrm{~mm}$. Flotation experiments were performed on laboratory flotation machines with the volume of chambers 1,5; 0,$75 ; 0,5$ liters. Experiments were performed in the closed cycle. The scheme of flotation included regrinding, the main flotation, control, and two retreatment operations of the gold-containing concentrate. In the experiment 8 pieces of tailings, $0.5 \mathrm{~kg}$ each were used. In the process of regrinding, they used soda to create a pH of the environment equal to 8.0-8.5. The time of flotation operations was: basic flotation was 15 minutes, control flotation was 10 minutes, the first retreatment was 8 minutes, the second retreatment was 6 minutes. The following reagents were used: as a collector was sodium butyl xanthate and composite flotation (CF) reagent; as a foaming agent was T-92. The ratio of solid to liquid in flotation was 1:3. The flotation pulp after regrinding was stirred with the collector $(2 \mathrm{~min})$ and foaming agent (1.5 $\mathrm{min}$ ) without air supply at a rotor speed of $1300 \mathrm{rpm}$. After atmospheric air supply flotation treatment of pulp was performed according to the applied scheme of enrichment.

The optimum reagent conditions of flotation tailings processing were selected: the degree of regrinding of $95 \%$ of grade $-0,074 \mathrm{~mm}$, the consumption of sodium butyl xanthate of $100 \mathrm{~g} / \mathrm{t}$, the consumption of foaming agent T-92 of $30 \mathrm{~g} / \mathrm{t}$. Under the chosen reagent mode the gold-containing concentrate containing $6,4 \mathrm{~g} / \mathrm{t}$ gold at the recovery of $49,68 \%$ was obtained. Preliminary tailings regrinding increases the recovery of gold in the rough concentrate by $27,96 \%$. The results of the research are presented in Table 3.

Table 3. Results of flotation of gold-containing tailings using regrind

\begin{tabular}{|c|c|c|c|c|}
\hline Product name & $\begin{array}{l}\text { Yield, } \\
\%\end{array}$ & Au content, $\mathrm{g} / \mathrm{t}$ & Au extraction, $\%$ & Note \\
\hline Concentrate & 2.23 & 5.409 & 21.72 & \multirow{7}{*}{$\begin{array}{l}\text { Basic mode without } \\
\text { regrinding. Initial tailings } \\
\text { fineness } 88.0 \% \text { of } 74 \mu \mathrm{m} \\
\text { class }\end{array}$} \\
\hline Industrial product 2 & 5.02 & 1.096 & 9.91 & \\
\hline Industrial products 1 & 1.85 & 0.77 & 2.56 & \\
\hline Foam composite & 4.91 & & 3.89 & \\
\hline flotation agent & & 0.44 & & \\
\hline Tailings & 85.99 & 0.40 & 61.92 & \\
\hline Initial tailings & 100.00 & 0.56 & 100.00 & \\
\hline Concentrate & 4.93 & 6.4 & 49.68 & \multirow{7}{*}{$\begin{array}{l}\text { Grinding } \\
95.0 \% \text { of } 74 \mu \mathrm{m} \text { class }\end{array}$} \\
\hline Industrial products 2 & 2.79 & 0.92 & 4.04 & \\
\hline Industrial products 1 & 3.91 & 0.62 & 3.82 & \\
\hline Foam composite & 4.18 & & 2.70 & \\
\hline flotation agent & & 0.41 & & \\
\hline Tailings & 84.19 & 0.3 & 39.77 & \\
\hline Initial tailings & 100.00 & 0.64 & 100.00 & \\
\hline
\end{tabular}

In the process of regrinding of gold-containing technogenic raw materials for a more complete opening of mineral aggregates, ultra- and micro-dispersed gold particles, covered with oxide films of iron and quartz, are formed. They are practically not captured by ordinary sulfide flotation. The applied microheterogeneous emulsion of composite flotation agent possesses simultaneously aggregation and flotation ability in relation to ultrafine gold minerals to carriers, covered with oxide films of iron and quartz.

At use in flotation of the composition of collectors, the mechanism of their interaction with a surface of minerals is defined by features of a surface of minerals and the activity of each component of the collector. At dispersion besides microbubbles the microemulsion is formed, which at collision with slurry particles of minerals spreads and hydrophobized their surface, improving the process of their flotation. Microbubbles in turn are much easier to fix on such hydrophobic surfaces of slam particles.

The reagent mode of flotation of gold-containing tailings using composite flotation (CF) agent, which is a mixture of sodium butyl xanthogenate and Realflot was tested. The composite flotation (CF) agent was used in the form of an emulsion obtained in a T18 digital ULTRA-TURRAX dispersant. The particle sizes of a microemulsion of composite flotation (CF) agent were measured on the laser particle analyzer 
Winner2000E. The optimum ratio of sodium butyl xanthate to the reagent in the composite reagent was defined, which was 85:15 and the optimum reagent consumption in the main flotation was $80 \mathrm{~g} / \mathrm{t}$. The content of particles smaller than 20.8 microns in the composite reagent with a ratio of sodium butyl xanthogenate and Reaflot $85: 15$ percent is $26 \%$ (Figure 2 ).

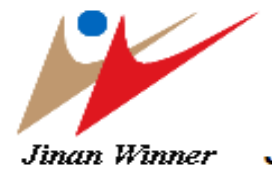

\section{Jinan Winner}

Measuring range:0.1-300um

\section{Laser Particle Sizer Testing Report \\ Winner2000E}

\begin{tabular}{|c|c|}
\hline Sample Information & \\
\hline $\begin{array}{l}\text { Sample Name:Test } \\
\text { Sample refractive index: } 1.51-\mathrm{i}^{\star} 0.100\end{array}$ & $\begin{array}{l}\text { Sample source: } \\
\text { Sample density: } 1 \mathrm{~g} / \mathrm{cm}^{\wedge} 3\end{array}$ \\
\hline Testing Information & \\
\hline UltraSonic Time:120s & Testing enterprise: \\
\hline Disperse medium:1 & Measured by: \\
\hline Dispersant: 1 & Measuring Time:01.06.2021 12:40:42 \\
\hline
\end{tabular}

Analyse Result(Analysis mode:Free distribution Statistics-Mode: By Volume distribution)

$\mathrm{D} 50=37.327 \mathrm{um} \quad \mathrm{S} /=4992.158 \mathrm{~cm}^{\wedge} 2 / \mathrm{cm}^{\wedge} 3 \quad \mathrm{D}[4,3]=38.661 \mathrm{um}$

$\mathrm{D} 90=68.231 \mathrm{um} \quad \mathrm{S} / \mathrm{g}=4992.158 \mathrm{~cm}^{\wedge} 2 / \mathrm{g} \quad$ Fitting deviation:0.005

Optics Concentration: 33.5

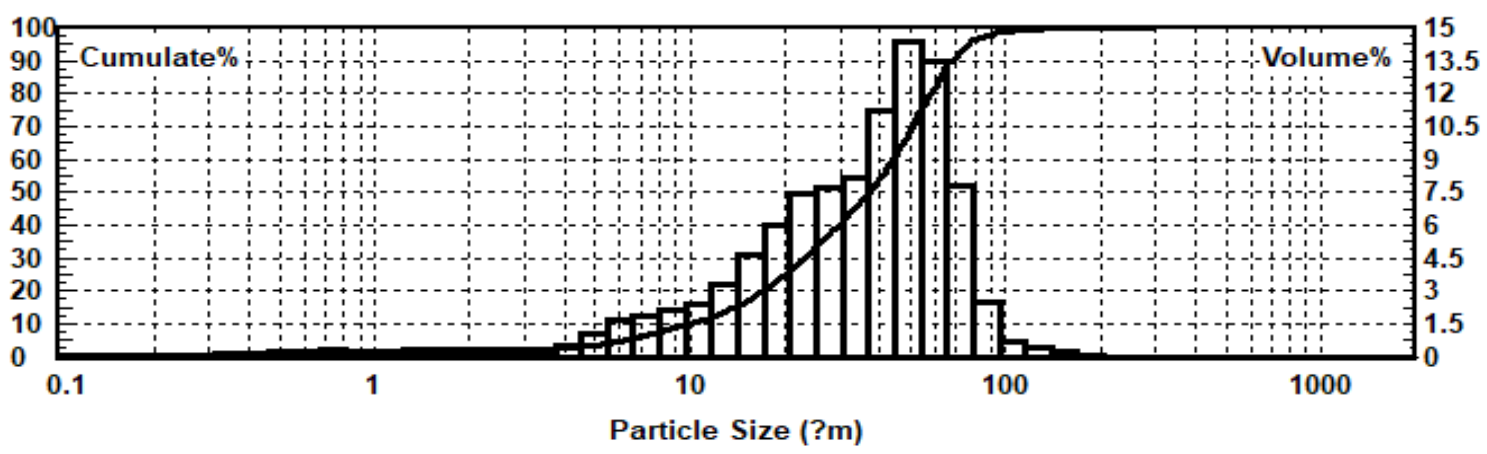

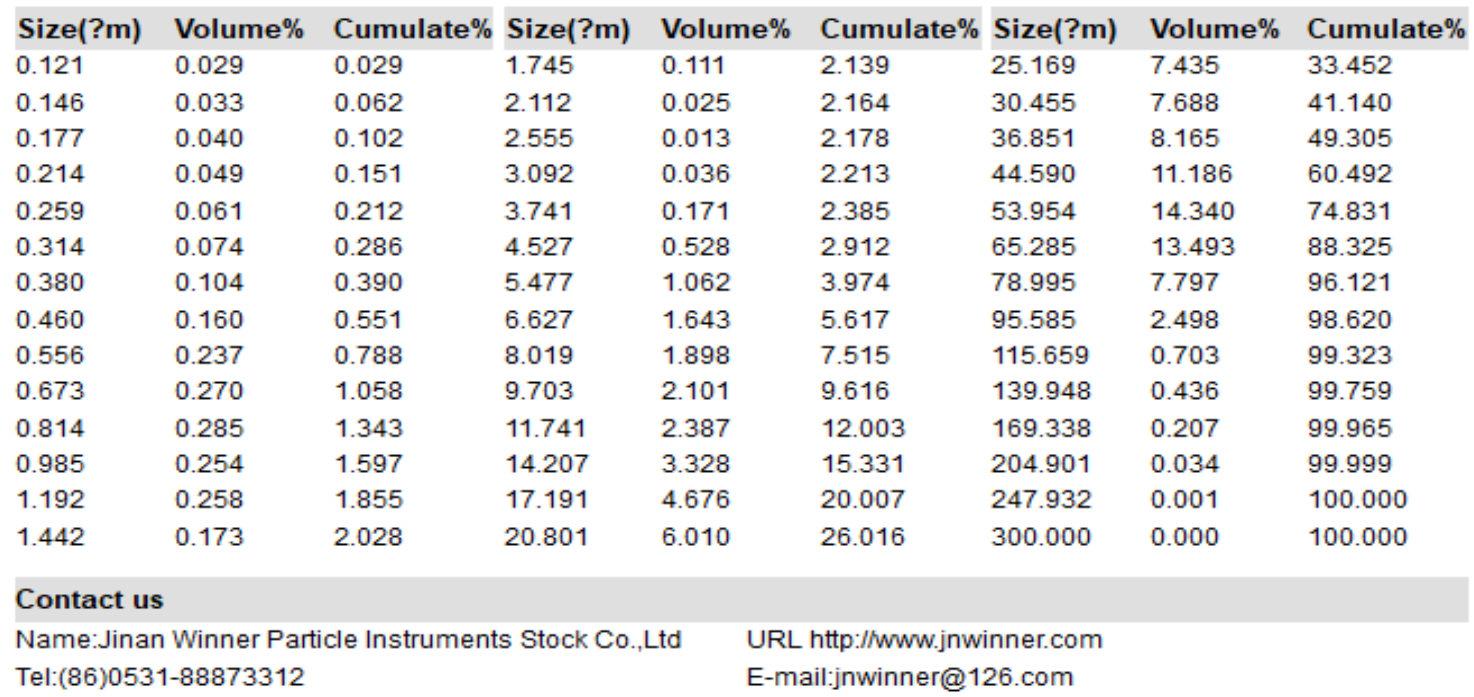

Fig. 2. Distribution of composite reagent particles with the ratio butyl xanthogenate $:$ Reaflot $=85: 15$

The results of flotation of gold-containing tailings using the composite reagent are presented in Table 4. 
Table 4. Results of flotation tailings using composite reagent

\begin{tabular}{|c|c|c|c|c|}
\hline Product name & Yield,\% & Au content, g/t & Au extraction,\% & Note \\
\hline Concentrate & 4.01 & 9.1 & 54.33 & \multirow{6}{*}{$\begin{array}{l}\text { Total consumption of } \\
\text { composite reagent } 80 \\
\mathrm{~g} / \mathrm{t}\end{array}$} \\
\hline Industrial products 2 & 2.46 & 1.0 & 3.66 & \\
\hline Industrial products 1 & 3.65 & 1.1 & 5.98 & \\
\hline $\begin{array}{l}\text { Foam composite } \\
\text { flotation agent }\end{array}$ & 3.98 & 0.9 & 5.33 & \\
\hline Tailings & 85.9 & 0.24 & 30.7 & \\
\hline Initial tailings & 100.0 & 0.672 & 100.0 & \\
\hline
\end{tabular}

At an optimum consumption of the composite reagent of $80 \mathrm{~g} / \mathrm{t}$, a gold-containing concentrate containing $9.1 \mathrm{~g} / \mathrm{t}$ gold was obtained with a recovery of $54.33 \%$. Application of composite reagent increases gold recovery into concentrate, in comparison with the basic mode, by $4.65 \%$ with a reduction of its consumption by $20 \%$.

\section{Conclusions}

The paper presents the results of laboratory research on flotation processing of gold-containing tailings using the composite flotation (CF) agent. The composite flotation (CF) agent is a microemulsion of sodium butyl xanthogenate and Realflot composition. The gold concentrate with a gold content of $6.4 \mathrm{~g} / \mathrm{t}$ and recovery of $49.68 \%$ was obtained in the basic mode. The use of the composite flotation (CF) agent increases the recovery of gold in the gold concentrate by $4.65 \%$, compared with the basic collector sodium butyl xanthate. The consumption of the composite flotation (CF) agent is reduced by $20 \%$.

\section{Acknowledgments}

The work was executed at the Institute of metallurgy and enrichment in Almaty, the Republic of Kazakhstan with the financial support of the Committee of Science of the Ministry of Education and Science of the Republic of Kazakhstan under grant No. P09259372.

Cite this article as: Semushkina L.V.; Narbekova S.M. (2021). On the possibility of flotation processing of technogenic gold-containing waste from enrichment plants. Challenges of Science. Issue IV, 2021, pp. 40-47. https://doi.org/10.31643/2021.06

\section{References}

1. Chanturiya V.A., Matveeva T.N., Ivanova T.A., Getman V.V. (2016) Mechanism of interaction of clouc point polymers with platinum and gold in flotation of finely disseminated precious metal ores. Mineral Processing and Extractive Metallurgy Review, Vol.37, No.3, pp.187-195. https://doi.org/10.1080/08827508. 2016.1168416.

2. Magomedov D.R., Koizhanova A.K. (2018) Oxidative leaching of gold from sorption tailings using surfactants and oxidizing agents. Materials of International Practical Internet Conference "Challenges of Science", pp.217-222. https://doi.org/10.31643/2018.031

3. Abdykirova G.Zh., Kenzhaliev B.K., Koizhanova A.K., Magomedov D.R. (2020) Low-sulfide gold-quartz ore concentration potential study. Ore Beneficiation. №3, P.14-18. DOI: 10.17580/or.2020.03.03.

4. Matveyeva T.N., Chanturia V.A., Gapchich A.O. (2017) Extraction of fine micro- and nanoparticles of gold using a thermomorphic polymer with a functional group of diphenylphosphine. Physical and technical problems of mineral development. No. 3. pp.131-140.

5. Kianinia Y., Khalesi M. R., Abdollahy M., Khodadadi Darban A. (2019) Leaching of gold ores with high cyanicides: a physicochemical modeling approach. Journal of Mining and Environment. Vol.10. No.1. pp.87-94. 
6. Yerdenova M.B., Kozhanova A.K., Kamalov E.M., Abdyldaev N.N., Abubakriev A.T. (2018) Additional extraction of gold from waste processing of gold-bearing ores of Kazakhstan. Complex use of mineral resources. No. 2. pp.12-20. http://kims-imio.kz.

7. Semushkina L.V., Turysbekov D.K., Mukhanova A.A., Narbekova S.M., Mukhamadilova A.M. (2018) Processing of tailings of flotation of ores of Kazakhstan deposits using a modified flotation agent. Complex use of mineral resources. No. 1. pp.5-11. http://kimsimio.kz..

8. Ivanova T.A., Zimbovsky I.G., Hetman V.V., Karkeshkina A.Yu. (2018) Investigation of the possibility of using dithiopyrylmethane in the flotation of sulfide minerals. Ore Beneficiation. No. 6. pp.38-44.

9. Algebraistova N.K., Samorodsky P.N., Kolotushkin D.M., Prokopyev I.V. (2018) Technology of gold extraction from goldcontaining technogenic raw materials. Ore Beneficiation. No. 1. pp.33-37.

10. Fatahi M. R., Farzanegan A. (2017) DEM simulation of laboratory Knelson concentrator to study the effects of feed properties and operating parameters Advanced Powder Technology. Vol.28. Iss.6. pp.1443-1458. DOI: 10.1016/j.apt.2017.03.011.

11. Xiao J., Liu G., Zhong H., Huang Y., Cao Z. (2017) The flotation behavior and adsorption mechanism of O-isopropyl-S-[2(hydroxyimino)propyl] dithiocarbonate ester to chalcopyrite. Journal of the Taiwan Institute of Chemical Engineers. No.71. pp.38-46.

12. Gusev V.Yu., Radushev A.V., Chekanova L.G., Baigacheva E.V., Manylova K.O., Gogolishvili V.O. (2018) Nitrogen derivatives of phenol and 1-naphthol as collectors for flotation of sulfide ores of non-ferrous metals. Journal of Applied Chemistry. No. 4. pp.503512.

13. Algebraistova N.K., Golsman D.A., Kolotushkin D.M., Prokopyev I.V. (2018) Technological evaluation of stale tailings processing of gold-containing low-sulfide ore. Non-ferrous metals. No. 5. pp.25-30. DOI: 10.17580/tsm.2018.05.03.

14. Nikolayyev A.A., So Tu, Goryachev B.E. (2016) Criterion of selectivity of the collector's action in collective-selective flotation cycles of sulfide ores. Ore Beneficiation. No. 4. pp.23-28.

15. Ryaboy V.I., Shepeta E.D., Kretov V.P., Levkovets S.E., Ryaboy I.V. (2015) Effect of surface-active properties of reagents containing sodium dialkyldithiophosphates on sulfide flotation. Ore Beneficiation. No. 2. pp.18-22. 